\title{
Amitraz marker residues in honey from honeybee colonies treated with Apiwarol
}

\author{
Krystyna Pohorecka ${ }^{1}$, Tomasz Kiljanek ${ }^{2}$, Maja Antczak ${ }^{2}$, \\ Piotr Skubida ${ }^{3}$, Piotr Semkiw ${ }^{3}$, Andrzej Posyniak ${ }^{2}$ \\ ${ }^{1}$ Department of Honey Bee Diseases, ${ }^{2}$ Department of Pharmacology and Toxicology, \\ National Veterinary Research Institute, 24-100 Pulawy \\ ${ }^{3}$ Department of Apiculture, Research Institute of Horticulture, 96-100 Skierniewice \\ krystyna.pohorecka@piwet.pulawy.pl
}

Received: June 15, $2018 \quad$ Accepted: September 27, 2018

\begin{abstract}
Introduction: Amitraz is a formamide exhibiting both acaricidal and insecticidal activity and is frequently used by beekeepers to protect honeybee colonies against Varroa destructor mites. The aim of this apiary trial was to evaluate the impact of honeybee colony fumigation with amitraz on the level of contamination of honey stored in combs. Material and Methods: Experimental colonies were fumigated four times every four days with one tablet of Apiwarol per treatment. Honey was sampled from combs of brood chambers and combs of supers one day after each amitraz application and from harvested honey. Amitraz marker residues (as a total of amitraz and metabolites containing parts of molecules with properties specific to the 2,4-DMA group, expressed as amitraz) were evaluated in honey. Results: All analysed samples were contaminated with amitraz metabolites. 2,4-DMA and DMPF were the most frequently determined compounds. The average concentration of amitraz marker residue in honey from groups where a smouldering tablet was located directly in beehives was significantly higher than that of residue in honey from groups with indirect smoke generation. No significant effect on the honey contamination deriving from the place where it was exposed to smoke (combs of brood chambers and supers) was noted. Amitraz marker residues exceeded the MRL in $10 \%$ of honey samples from combs. Conclusion: Fumigation of beehives with amitraz results in contamination of honey stored in combs.
\end{abstract}

Keywords: honey bees, honey, Varroa destructor, amitraz fumigation, amitraz marker residues.

\section{Introduction}

Amitraz as a formamide insecticide and acaricide is used for the control of animal ectoparasites. It is one of the main and more commonly applied acaricides against Varroa destructor, the external parasite of honey bees $(1,8,11)$. In beekeeping, there are two possible methods of administration of amitraz: longlasting contact polyethylene strips saturated with the insecticide and short-lasting combustible tablets for fumigation of colonies. In Poland, chemical combat of Varroa mites is undertaken much more frequently by the second means with the usage of the formulation under the trade name Apiwarol (18). Apiwarol has the form of tablets, each containing $12.5 \mathrm{mg}$ of amitraz. Immediately following ignition, the tablet burns flamelessly which results in the release of amitraz into the air. According to the manufacturer's recommendations, honeybee colonies should be fumigated with Apiwarol twice during spring and two to three times in autumn. Nevertheless, the popular treatment scheme is to decrease the Varroa infection level in summer (in July and August), before harvesting the late variety of honey (18). The treated colonies should not have merchantable honey stocks at the time of carrying out this medical procedure. Thus, spring and summer operations pose a particularly high risk to honey pollution and human health.

Amitraz is unstable and undergoes rapid biotransformation in the low $\mathrm{pH}$ environment of the hive. The metabolism of amitraz in bees has not been investigated (6). It is known that the amitraz molecule hydrolyses through the intermediate metabolites N-2,4-dimethylphenyl-N-methylformamidine (DPMF) 
and N-2,4-dimethylphenylformamide (DMF), to form the environmentally stable toxic compound 2,4-dimethylaniline (2,4-DMA) $(2,10,12)$. The analysis of honey samples enriched with amitraz under laboratory conditions leads to the conclusion that the main amitraz metabolites in honey are DMF and DMPF with rather low concentrations of 2,4-DMA residues $(15,16)$.

The Commission Regulation (EU) No. 37/2010 on pharmacologically active substances and their classification regarding maximum residue limits in food stuffs of animal origin defines amitraz marker residues as the sum of amitraz and all metabolites containing the 2,4-DMA moiety, expressed as amitraz. The maximum residue level (MRL) of amitraz in honey is $200 \mu \mathrm{g} / \mathrm{kg}$ (4). In order to harmonise the MRLs for certain substances including amitraz, the European Commission planned to transcribe the veterinary MRLs into pesticide MRL legislation (6).

The issue of honey contamination with amitraz is differently interpreted by different pieces of research. The results of certain investigations, particularly those published earlier, indicate a very low risk of honey pollution after treatment of honeybee colonies with amitraz $(9,17)$. In contradiction, the European Food Safety Authority (EFSA) report on pesticide residues in food indicates that amitraz residues are among the most common pesticides determined in honey in the EU (5, 7). It should be emphasised that so far there has been no research on the presence of amitraz metabolites in samples of honey, other bee products, wax, or the bees collected from bee colonies where drugs containing amitraz were applied experimentally by fumigation.

The study was designed to evaluate the concentration of amitraz marker residues in honey harvested after Varroa mite control, using amitraz (Apiwarol) in the form of fumigation treatments.

\section{Material and Methods}

Honeybee colonies. The field study was conducted in the experimental apiary of the Research Institute of Horticulture in the Department of Apiculture in Pulawy. The experiment was carried out on 24 honeybee colonies maintained in Wielkopolski hives (frame size $360 \mathrm{~mm} \times 260 \mathrm{~mm}$ ), equipped with deep bottom boards. All Apis mellifera carnica and Apis mellifera caucasica honeybee colonies were naturally infected with $V$. destructor. Each colony settled two hive boxes (brood chamber and honey super) with the queen excluder separate. In each hive box, there were 10 frames (one-year combs and combs which had been built by bees in the season during which the experiment was carried out). Before starting the trial, colonies were monitored to estimate the bee population (the number of combs covered by bees and brood area). Honeybee colonies were subsequently divided into two homogeneous groups of 12 hives in each.

Amitraz treatment. Twelve honeybee colonies of a group designated B were fumigated four times every four days $\left(13^{\text {rd }}, 17^{\text {th }}, 21^{\text {st }}\right.$, and $25^{\text {th }}$ August 2015.) with one tablet of Apiwarol per treatment. A smouldering tablet was located directly on the bottom board of the beehives, and the entrances of hives during fumigation were closed. A single treatment took approximately $20 \mathrm{~min}$. Each treatment was performed in the evening, after the end of the bees' flight. Treatments of 12 honeybee colonies of the second group designated $\mathrm{W}$ were given at the same time, but with indirect smoke generation. The difference was that the tablets were combusted in a Wakont electric fumigator (Wakont, Poland) and not directly on the bottom board of beehives. The smoke created in this equipment was then introduced to entrances of hives through a nozzle. The honeybee colonies had not received any amitraz treatment for two years before the field trials.

Honey sampling in colonies. On the day after each amitraz application individual samples of honey (both from combs of brood chambers and combs of supers) were taken from three beehives of group B and from three beehives of group W. Samples of honey after each treatment were collected from other honeybee colonies. Honey from combs of the brood chambers and supers of groups $\mathrm{B}$ and $\mathrm{W}$ was centrifuged separately. After the harvesting finished, the three samples of centrifuged honey from group B and three from group $\mathrm{W}$ were subjected to analysis. Honey samples were stored for three weeks at $4^{\circ} \mathrm{C}$ until analysis.

Chemical analysis of amitraz residues. The method for the determination of the amitraz metabolites 2,4-DMA, DMF, and DMPF was the same as that already described for honeybee samples (14). First, the honey sample ( $5 \mathrm{~g}$ ) was spiked with acetamiprid-D3 as an internal standard. Next, $10 \mathrm{~mL}$ of water and glass beads were added, and the sample was shaken. The sample was extracted with $10 \mathrm{~mL}$ of $1 \%$ acetic acid in acetonitrile and shaken again. Sodium acetate in a $1 \mathrm{~g}$ mass and magnesium sulphate at $4 \mathrm{~g}$ were added, the sample was shaken a further time and centrifuged. Then, a $7 \mathrm{~mL}$ aliquot of the acetonitrile phase was subjected to clean-up by dispersive solid phase extraction (D-SPE), using $350 \mathrm{mg}$ of PSA, $350 \mathrm{mg}$ of Z-Sep + , and $1,050 \mathrm{mg}$ of magnesium sulphate. After shaking and centrifugation, $0.5 \mathrm{~mL}$ of supernatant was transferred into an injection vial with a $0.2 \mu \mathrm{m}$ PTFE filter. The final extract was analysed by LC-MS/MS. Briefly, analyses were carried out using an Agilent 1260 HPLC system (Agilent, Germany) equipped with a Phenomenex Luna Phenyl-Hexyl (3 mm, 150 $\times 2.0 \mathrm{~mm}$ ) column (Phenomenex, USA). An AB Sciex QTRAP 6500 LC-MS/MS system (AB Sciex, USA) was used in the scheduled MRM advanced mode with 
TurboIon Spray ion source in positive ionisation for the mass spectrometric analysis. The method allows determination of DMA at the level $\geq 10 \mu \mathrm{g} / \mathrm{kg}$ and of DMF and DMPF at levels $\geq 1 \mu \mathrm{g} / \mathrm{kg}$ (limits of quantification, LOQ). At the initial stage, samples were extracted with acetonitrile in order to check whether amitraz itself was present in honey.

Statistical analysis. Data were expressed as mean \pm standard deviation (SD). Before performing the statistical analysis, data were examined for normality and variance homogeneity as parametric test assumptions. The significance of differences in mean values of amitraz concentration in honey was determined using a Student's $t$-test and ANOVA for variables with the normal distribution. The MannWhitney $U$ test and the ANOVA rank Kruskal-Wallis test were used to compare mean values in the absence of the normal distribution variables. All the statistical analyses were carried out using Statistica 10 (StatSoft, USA). $\mathrm{P} \leq 0.05$ was considered to indicate statistical significance.

\section{Results}

All analysed honey samples from both groups ( $\mathrm{n}=54)$ were contaminated. At least one amitraz metabolite was found in each sample, however, no residues of parent amitraz were detected. The most frequently determined compound was 2,4 DMA, although around $80 \%$ of samples contained DMPF (Table 1). The mean concentrations of 2,4-DMA in honey samples collected in both groups one day after the fumigation were significantly higher than those of DMF and DMPF $(\mathrm{P} \leq 0.05)$. Similar proportionality was observed for the amitraz metabolite profile in the centrifuged honey. After Apiwarol fumigation with the electric fumigator, DMF concentrations in centrifuged honey were lower than the LOQ $(1 \mu \mathrm{g} / \mathrm{kg})$, whilst DMPF and 2,4-DMA values ranged from 1.0 to $1.3 \mu \mathrm{g} / \mathrm{kg}$ (on average $1.13 \mu \mathrm{g} / \mathrm{kg}$ ) and from 13.0 to $35.2 \mu \mathrm{g} / \mathrm{kg}$ (on average $23.2 \mu \mathrm{g} / \mathrm{kg}$ ), respectively. After treatment of honeybee colonies with Apiwarol by smouldering tablet directly in hives, residues of DMF, DMPF, and 2,4-DMA in centrifuged honey reached mean levels of $2.3 \mu \mathrm{g} / \mathrm{kg}$ (from 1.9 to $2.6 \mu \mathrm{g} / \mathrm{kg}$ ), $2.4 \mu \mathrm{g} / \mathrm{kg}$ (from 1.9 to $2.9 \mu \mathrm{g} / \mathrm{kg}$ ), and $84.9 \mu \mathrm{g} / \mathrm{kg}$ (from 68.6 to $98.4 \mu \mathrm{g} / \mathrm{kg}$ ), respectively.

The findings of total amitraz marker residue concentrations in honey samples, expressed according to the Commission Regulation (EU) No. 37/2010 (as sum of amitraz and all metabolites containing the 2,4-DMA moiety, expressed as amitraz), are presented in Table 2. For the group which was fumigated with the electric fumigator, amitraz concentration ranged between 5.2 and $146 \mu \mathrm{g} / \mathrm{kg}$ (mean $62.9 \mu \mathrm{g} / \mathrm{kg}$ ) in the honey collected after the sequence of four treatments and from 34.5 to $87.5 \mu \mathrm{g} / \mathrm{kg}$ (mean $58.3 \mu \mathrm{g} / \mathrm{kg}$ ) in extracted honey. The MRL was not exceeded in any of the honey samples taken from beehives fumigated indirectly with the Wakont fumigator. Amitraz residues in honey after tablet combustion directly in the hive ranged from 9.4 to $766 \mu \mathrm{g} / \mathrm{kg}$ after the sequence of four treatments and from 176 to $248 \mu \mathrm{g} / \mathrm{kg}$ after honey harvesting. The mean residue concentrations of amitraz were 109 and $214 \mu \mathrm{g} / \mathrm{kg}$ for these two periods, respectively. Quantities of amitraz exceeding the MRL were found in five honey samples: in three samples collected after the four Apiwarol applications and in two samples of the extracted honey (also after the four Apiwarol applications).

The average concentration of amitraz in honey of group B was significantly higher than that in honey of group $\mathrm{W}(\mathrm{P}<0.05)$. No significant effect on honey contamination deriving from the place of its exposure to smoke (combs of brood chambers and supers) was noted $(\mathrm{P}>0.05)$. A wide range of amitraz concentration was proven both with regard to sampling sites and particular honeybee colonies. Treatment repetition with the Wakont did not significantly affect the rise of the concentration of amitraz metabolites in subsequent honey samples $(\mathrm{P}>0.05)$. The four applications of Apiwarol directly inside the beehives caused a clear increase in amitraz marker residues in honey, although this rise was found to be statistically insignificant $(\mathrm{P}>0.05)$.

Table 1. The amitraz metabolite profile in honey samples, separately presented for each group

\begin{tabular}{|c|c|c|c|c|}
\hline \multirow{3}{*}{ Metabolite } & \multicolumn{2}{|c|}{ Group W - Apiwarol combustion in Wakont $(\mathrm{n}=27)$} & \multicolumn{2}{|c|}{ Group B - Apiwarol combustion in hive $(\mathrm{n}=27)$} \\
\hline & \multirow{2}{*}{$\begin{array}{l}\text { percentage in samples } \\
\text { containing residue }\end{array}$} & Concentration $(\mu \mathrm{g} / \mathrm{kg})$ & \multirow[b]{2}{*}{$\begin{array}{l}\text { percentage of samples } \\
\text { containing residue }\end{array}$} & Concentration $(\mu \mathrm{g} / \mathrm{kg})$ \\
\hline & & Min. Max. Mean & & Min. Max. Mean \\
\hline DMF & $37.0 \%$ & $1.1 \quad 3.8 \quad 1.6 \mathrm{a}$ & $66.6 \%$ & $1.0 \quad 29.9 \quad 4.6 \mathrm{a}$ \\
\hline DMPF & $77.7 \%$ & $\begin{array}{lll}1.0 & 2.7 \quad 1.7 \mathrm{a}\end{array}$ & $81.4 \%$ & $1.0 \quad 16.4 \quad 4.1 \mathrm{a}$ \\
\hline DMA & $92.5 \%$ & $10.060 .526 .6 \mathrm{~b}$ & $96.1 \%$ & $10.0309 .548 .1 \mathrm{~b}$ \\
\hline
\end{tabular}

${ }^{\mathrm{a}-\mathrm{b}}$ means with different small letters in the same column are significantly different $(\mathrm{P} \leq 0.05)$ 
Table 2. Average amitraz marker residue contents in honey samples \pm SD (as sum of amitraz and all metabolites containing the 2,4-DMA moiety, expressed as amitraz, in $\mu \mathrm{g} / \mathrm{kg}$ )

\begin{tabular}{|c|c|c|c|c|c|c|c|c|}
\hline Groups & \multicolumn{4}{|c|}{ Group W - Apiwarol combustion in Wakont } & \multicolumn{4}{|c|}{ Group B - Apiwarol combustion in hive } \\
\hline Consecutive treatment & $\begin{array}{l}1^{\text {st }} \\
\mathrm{n}=6\end{array}$ & $\begin{array}{l}2^{\text {nd }} \\
\mathrm{n}=6\end{array}$ & $\begin{array}{l}3^{\text {rd }} \\
\mathrm{n}=6\end{array}$ & $\begin{array}{l}4^{\text {th }} \\
n=6\end{array}$ & $\begin{array}{l}1^{\text {st }} \\
\mathrm{n}=6\end{array}$ & $\begin{array}{l}2^{\text {nd }} \\
\mathrm{n}=6\end{array}$ & $\begin{array}{l}3^{\text {rd }} \\
\mathrm{n}=6\end{array}$ & $\begin{array}{l}4^{\text {th }} \\
n=6\end{array}$ \\
\hline Samples from brood chamber & $71.7 \pm 52.9$ & $16.3 \pm 11.1$ & $54.9 \pm 2.1$ & $56.3 \pm 50.4$ & $38.1 \pm 14.3$ & $41.1 \pm 31.1$ & $91.5 \pm 55.9$ & $276.2 \pm 288.9$ \\
\hline Samples from super & $75.1 \pm 18.9$ & $38.4 \pm 7.8$ & $106.8 \pm 0.8$ & $72.2 \pm 27.1$ & $69.5 \pm 9.9$ & $85.1 \pm 26.8$ & $53.9 \pm 19.3$ & $150.0 \pm 70.1$ \\
\hline In total & $73.4 \pm 39.8$ & $27.4 \pm 14.7$ & $80.9 \pm 26.0$ & $64.3 \pm 41.3$ & $53.8 \pm 20.0$ & $63.1 \pm 36.4$ & $72.7 \pm 45.8$ & $213.1 \pm 219.5$ \\
\hline $\begin{array}{l}\text { Samples from centrifuged honey } \\
\mathrm{n}=3 \text { in each group }\end{array}$ & \multicolumn{4}{|c|}{$58.3 \pm 21.98 \mathrm{a}$} & \multicolumn{4}{|c|}{$214.4 \pm 29.7 b$} \\
\hline
\end{tabular}

${ }^{\mathrm{a}-\mathrm{b}}$ means with different small letters in the same row are significantly different $(\mathrm{P} \leq 0.05)$

\section{Discussion}

Apiwarol fumigation of honeybee colonies is commonly used by Polish beekeepers to protect against $V$. destructor infection (18). Curative smoke spreads around the entire hive, allowing the medicine to reach as many bee-parasitising mites as possible. Residues of the parent substance (amitraz) were not detected in any of the samples tested despite the fact that they were taken on the day following the treatments. Analysis of the obtained results led to the conclusion that amitraz undergoes rapid biotransformation and is unstable in the environment of the hive or decomposes under the influence of the high temperature produced by the combustion of tablet. The effectiveness of fumigation in controlling mites indicates that the amitraz active substance is present in the smoke, although, on the other hand, some of its metabolites (e.g. DMPF) also show varroacidal activity.

Amitraz metabolite concentrations in honey stored in hives during Apiwarol treatment were unknown prior to this research. Research on honey contamination with amitraz after administration to honeybee colonies of other veterinary medicinal products with an amitraz component is also limited. After two long-lasting treatments with Apivar (strips with $500 \mathrm{mg}$ amitraz each, contact action, 42 days), no residue of the parent compound was detected in honey, regardless of the date of sampling, at the LOD 0.002 or at $0.01 \mathrm{mg} / \mathrm{kg}(9,17)$. Different results were obtained after long-lasting Apivar application when the three metabolites of amitraz were measured in honey as well as amitraz itself (20). Ten days after the end of treatment, amitraz residues in honey from supers ranged from 0.06 to $0.09 \mathrm{mg} / \mathrm{kg}$ and 15 days after ranged from below LOQ $(0.05 \mathrm{mg} / \mathrm{kg})$ to $0.08 \mathrm{mg} / \mathrm{kg}$. The exposure of bees to amitraz during treatment is disproportionately longer than during the Apiwarol method of application.

The breakdown of amitraz in honey spiked with amitraz and kept at room temperature has also been investigated $(2,10,12,15)$. Amitraz was found to be rapidly decomposed within 15 days. According to these authors, the main breakdown products of amitraz were 2,4-DMA, DMF, and DMPF, but the relative amounts of the degradation products were different. One author found relative amounts of DMPF, DMF, and DMA of 50,25 , and $25 \%(10)$, whereas another found $0 \%, 85 \%$, and $15 \%$ (12), respectively. The amitraz metabolite profile analysed after 15 days, by Korta et al (15) included 52\% DMPF, 44\% DMF, and 4\% DMA, and their measured concentrations of DPMF and DMF were stable in honey for at least 45 days. After testing amitraz stability in honeys from different geographical and botanical origins, this author maintains that the main residues found in honey after complete breakdown of amitraz are DMPF and DMF, and that only very small amounts $(<5 \%)$ of DMA are found. The disconcordant reports in the literature of the relative amounts of degradation products could be explained by a more complicated amitraz biotransformation scheme and existence of additional metabolites $(10,12)$. Even though amitraz has been commonly used for many years against varroosis, its metabolism has not been studied so far (6). For bees, both the European Medicines Agency (EMEA) and EFSA only extrapolate the metabolism of amitraz based on the amitraz metabolism pathways in other animal species and plants $(1,6)$. Additional reasons for this contradiction could be also differences in LOQ values between analytical methods, lack of determination of all amitraz metabolites containing the 2,4-DMA moiety, the time between amitraz treatment and the residue analysis, and the pharmaceutical form and route of administration.

Combustion of a single tablet with amitraz caused contamination of honey with amitraz metabolites. Rapid decomposition of amitraz and lack of parent residues would not mean that bee products are free from these toxic compounds, and it is pertinent that at least one amitraz metabolite was found in each analysed honey sample from this apiary trial. Concentration of amitraz residues is significantly higher when the Apiwarol tablet is administered directly into the hive. The manner of treatment (directly 
into the hive or introduced by the Wakont fumigator) has a significant impact on the concentration of amitraz residues when treatment is repeated several times.

The reports of EFSA confirm that amitraz residues in honey are a significant issue. It should be noted that amitraz residues in honey more likely originate from veterinary medicinal products used by beekeepers. According to the Commission Decision 2004/141/EC, amitraz is no longer approved as an active compound in plant protection products in the EU (3). Tests of beeswax and honeybee analysis also shed light on the issue of amitraz residues as a result of honeybee colony treatment $(13,19)$.

In conclusion, it seems necessary to review and update the knowledge relating to amitraz biotransformation in bees and the beehive environment.

Conflict of Interests Statement: The authors declare that there is no conflict of interests regarding the publication of this article.

Financial Disclosure Statement: This work was financially supported by statutory activity of the National Veterinary Research Institute in Pulawy and Research Institute of Horticulture in Skierniewice.

Animal Rights Statement: None required.

\section{References}

1. Amitraz. EMEA/MRL/572/99-FINAL Summary Report. February 1999

2. Bogdanov S.: Bestimmung von Amitraz und seine Metaboliten in Honig durch HPLC. Mitt Sekt Bienen FAM 1989, 3, 1-9.

3. Commission Decision 2004/141/EC of 12 February 2004 concerning the non-inclusion of amitraz in Annex I to Council Directive 91/414/EEC and the withdrawal of authorisations for plant protection products containing this active substance (Text with EEA relevance) (notified under document number C (2004) 332).

4. Commission Regulation (EU) No 37/2010 of 22 December 2009 on pharmacologically active substances and their classification regarding maximum residue limits in foodstuffs of animal origin. OJ L 15. 20.1.2010, 1-72.

5. EFSA (European Food Safety Authority): The 2014 European Union report on pesticide residues in food. EFSA J 2016, 14, 4611.
6. EFSA (European Food Safety Authority): Reasoned opinion on the setting of maximum residue levels for amitraz, coumaphos, flumequine, oxytetracycline, permethrin, and streptomycin in certain products of animal origin. EFSA J 2016, 14, 4570.

7. EFSA (European Food Safety Authority): The 2015 European Union report on pesticide residues in food. EFSA J 2017, 15, 4791.

8. FAO/WHO. Amitraz. (JMPR Evaluations Part II Toxicological). Monographs \& Evaluations 1998, No. 944.

9. Floris I., Satta A., Garau V.L., Melis M., Cabras P., Aloul N.: Effectiveness, persistence, and residue of amitraz plastic strips in the apiary control of Varroa destructor. Apidologie 2001, 32, 577-585.

10. Franchi A.; Severi A.: Comportamento dell'amitraz e dei suoi prodottti di degradazione nel miele. Presented at the $7^{\text {th }}$ Simposio Chimica degli Antiparassitari, Agricoltura e Informatica, Piacenza, Giugno, 1989, p. 89.

11. INCHEM. Amitraz (Pesticide residues in food: evaluations 1980). http://www.inchem.org/documents/jmpr/jmpmono/v080pr 02.htm.

12. Jimenez J.J., Bernal J.L., Del Nozal M.J., Toribio L., Atienza J.: Characterization and monitoring of amitraz degradation products in honey. J High Resolut Chrom 1997, 20, 81-84.

13. Kiljanek T., Niewiadowska A., Gaweł M., Semeniuk S., Borzęcka M., Posyniak A., Pohorecka K.: Multiple pesticide residues in live and poisoned honeybees - preliminary exposure assessment. Chemosphere 2017, 175, 36-44.

14. Kiljanek T., Niewiadowska A., Semeniuk S., Gaweł M., Borzęcka M., Posyniak A.: Multi-residue method for the determination of pesticides and pesticide metabolites in honeybees by liquid and gas chromatography coupled with tandem mass spectrometry - honeybee poisoning incidents. J Chromatogr A 2016, 1435, 100-114.

15. Korta E., Bakkali A., Berrueta L.A., Gallo B., Vicente F., Kilchenmann V., Bogdanov S.: Study of acaricide stability in honey. Characterization of amitraz degradation products in honey and beeswax. J Agric Food Chem 2001, 49, 5835-5842.

16. Korta E., Bakkali A., Berrueta L.A., Gallo B., Vincent P., Bogdanov S.: Determination of amitraz and other acaricide residues in beeswax. Anal Chim Acta 2003, 475, 97-103.

17. Martel A.C., Zeggane S., Aurières C., Drajnudel P., Faucon J.P., Aubert M.: Acaricide residues in honey and wax after treatment of honey bee colonies with Apivar ${ }^{\circledR}$ or Asuntol®50. Apidologie 2007, 38, 534-544.

18. Pohorecka K., Bober A., Skubida M., Zdańska D., Torój K.: A comparative study of environmental conditions, bee management, and the epidemiological situation in apiaries varying in the level of colony losses. J Apic Sci 2014, 58, 107-132.

19. Pohorecka K., Szczęsna T., Witek M., Miszczak A., Sikorski P.: The exposure of honey bees to pesticide residues in the hive environment with regard to winter colony losses. J Apic Sci 2017, 61, 105-125.

20. United States Environmental Protection, Memorandum: Amitraz. Crop Residue Field Trial for Honey and Honeycomb (Beeswax). Washington, D.C. 20460, 2012, 1-11. 